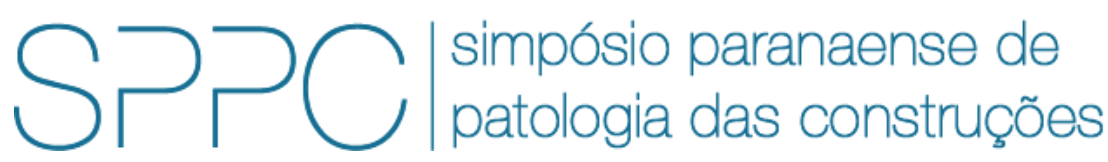

ISSN 2526-7248 artigo 2SPPC1025, pp. 303-314, 2017

\title{
Estudo do comportamento da barragem de Graus
}

\author{
Andressa Gobbi ${ }^{1}$, Sergio H. P. Cavalaro ${ }^{2}$ e Marcelo H. F. de Medeiros ${ }^{3}$ \\ ${ }_{1}^{1}$ Doutoranda, Universitat Politècnica de Catalunya, andressagobbi@yahoo.com.br \\ 2 Professor Doutor, Universitat Politècnica de Catalunya, sergio.pialarissi@upc.edu \\ ${ }^{3}$ Professor Doutor, Universidade Federal do Paraná, medeiros.ufpr@gmail.com
}

\begin{abstract}
Resumo: As barragens são de grande importância devido à sustentabilidade que garantem, pois permitem o abastecimento de águas, a irrigação, a produção de energia hidroelétrica, controle de cheias, atividades recreativas e navegação nos rios. Por razões técnicas e econômicas, em barragens de concreto é comum utilizar agregados da própria zona de localização das mesmas. Entretanto, estes agregados podem não ser os mais recomendáveis, pois sua qualidade e sua composição influenciam significativamente as possíveis patologias que podem ocorrer ao longo da vida útil das estruturas de concreto. Este estudo trata da avaliação da barragem de Graus, cujas principais manifestações patológicas são problemas expansivos que originaram mudanças dimensionais irreversíveis na sua estrutura. As principais causas dessa patologia são o ataque sulfático interno (ASI) somado a um segundo processo expansivo, baseado nas alterações visuais, na presença de fissuras e nos movimentos da barragem.
\end{abstract}

Palavras-chave: Agregado, reações expansivas, barragem de concreto.

Abstract: Dams have a great importance for the sustainability they provide because they allow supply, irrigation, hydroelectric power generation, flood control, recreation activities and river navigation. For technical and economical reasons in concrete dams is common to use aggregates of the same zone their location. However, those aggregates may not be the most recommended ones because its quality and composition influence significantly the possible pathologies that may occur along the useful life of the concrete structures. This study presents the evaluation of Graus' dam, whose main pathological manifestations are expansive problems that gave rise to irreversible dimensional changes in their structure. The main causes of this pathological manifestation are the internal sulphate attack (ISA) added to a second expansive process, based on the visual alterations, the presence of fissures and the movements of the dam.

Keywords: Aggregate, expansive reactions, concrete dam. 


\section{Introdução}

As barragens têm vida útil finita e atualmente apresentam uma taxa de falha geral de cerca de 1\% [1]. Isso ocorre porque a maior parte dessa estrutura está submersa e submetida a um ambiente consideravelmente agressivo. Umas das principais manifestações patologicas encontradas é a ocorrência de fissuras decorrentes da instabilidade dimensional causada por processos químicos expansivos.

O processo químico mais habitual em barragens de concreto é a reação álcaliagregado (RAA), amplamente estudada na bibliografia [2-4]. Outro tipo de reação expansiva é o ataque sulfático interno (ASI), que implica em diferentes reações químicas e é influenciado pela composição do cimento, natureza dos agregados, aditivos e fatores ambientais [5].

A Fig. 1 (a) apresenta a distribuição mundial de barragens com manifestações patológicas devido a processos expansivos [6, 7]. Das 113 barragens avaliadas, 98 apresentam expansões devido a reação álcali-sílica (RAS), 3 reação álcali carbonato (RAC), 6 estão afetadas por reação sulfática interna (RSI), 2 apresentam outros fatores expansivos e 6 estão sobre investigação. No caso da Espanha, 33\% das barragens apresentam RSI e $27 \%$ são afetadas por RAS, conforme observado na Fig. 1 (b).

a)

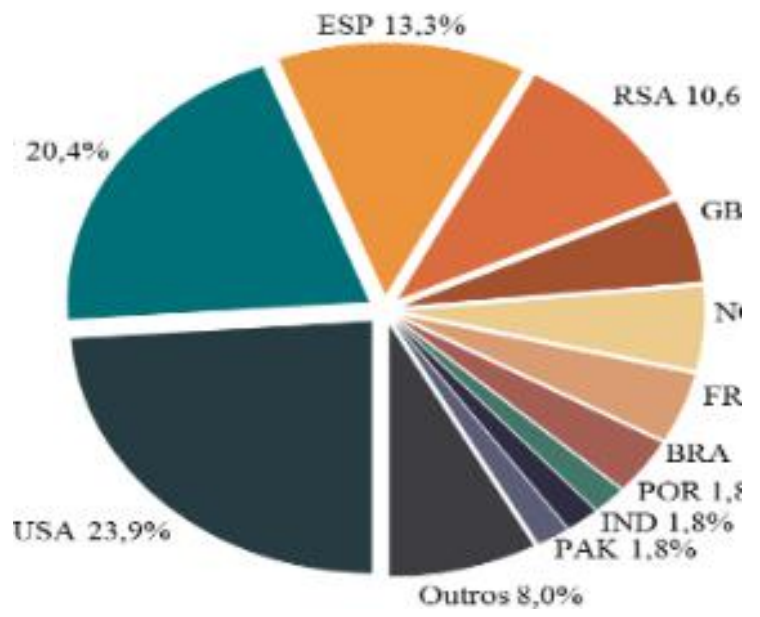

b)

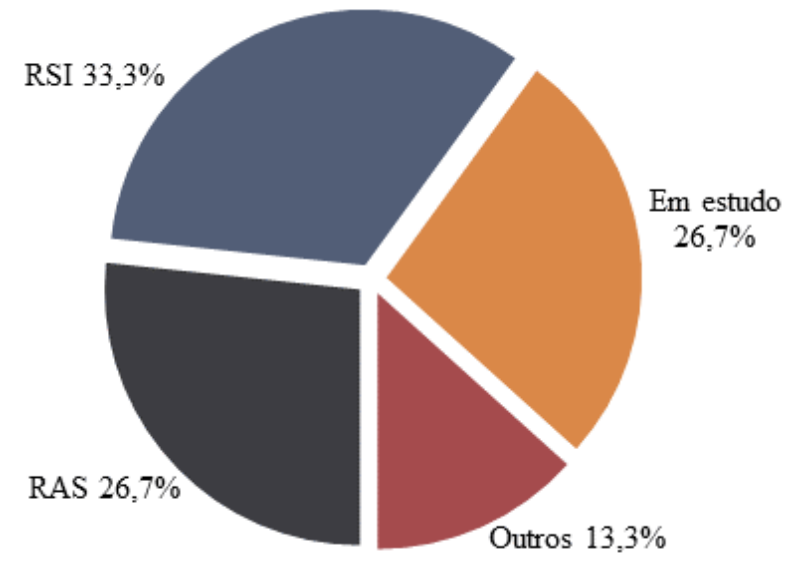

Figura 1: Número de barragens afetadas por expansão no mundo (a) e barragens com reações expansivas na Espanha (b).

O trabalho atual avalia a barragem de Graus, que apresenta manifestações patológicas como fissuras, alterações visuais, produtos de reação e movimentos não recuperáveis. As mudanças dimensionais produzidas pelos fenômenos expansivos no concreto podem se acumular ao longo da estrutura, dando lugar a movimentos não recuperáveis, este é o principal sintoma da barragem de Graus. Os demais estudos realizados na barragem de Graus [6, 9-13] ao longo dos anos demonstram não ser possível explicar o problema em sua totalidade apenas com a reação sulfática interna.

A metodologia aplicada se baseou na inspeção visual da barragem ao longo do tempo e análise dos deslocamentos coletados pelo sistema de auscultação. Com os 
resultados obtidos, foi possível verificar que existem dois mecanismos expansivos com cinéticas distintas atuando na barragem, uma mais rápida (RSI) e outra mais lenta (RAA).

\section{Estudo de caso}

Graus é uma barragem de concreto a gravidade, que se encontra na província de Lérida, na Espanha, ao longo do rio Tavascán (Fig. 2 [14]), que foi construída entre 1968-1971. A altura é de 28,90 m, enquanto o comprimento de crista é de 102,44 m, está dividida em 7 blocos. Possui vertedouro do tipo lâmina livre com capacidade de $205 \mathrm{~m}^{3} / \mathrm{s}$ e um volume total de $15.000 \mathrm{~m}^{3}$.
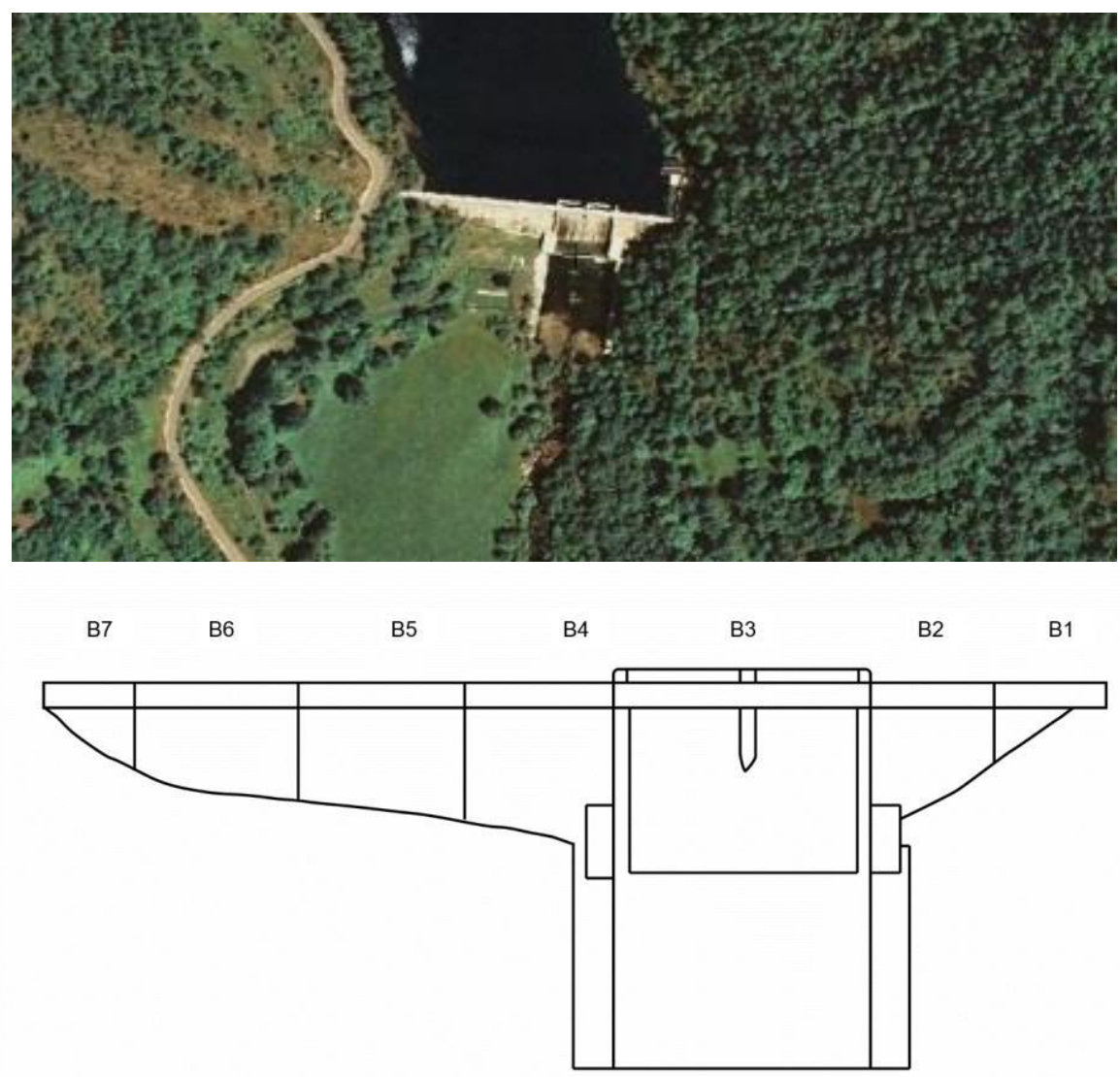

Figura 2: Barragem de Graus e esquemas dos blocos da barragem.

$\mathrm{Na}$ barragem de Graus, o sistema de auscultação foi instalado no ano de 1981, aproximadamente 10 anos depois de posta em operação e é composto por:

- 7 bases dispostas na crista e na galeria, que permitem determinar os movimentos horizontais e verticais. As bases fixas de referência, chamadas de 1 e 7, estão localizadas nas ombreiras da barragem;

- Pêndulos localizados nos blocos 2 e 4 com medições dos movimentos longitudinais e transversais.

A instrumentação é importante para o controle da barragem, permitindo uma análise rápida dos dados, com a detecção de um comportamento anômalo pelos responsáveis operacionais. Com um bom sistema de auscultação, pode-se iniciar as 
intervenções de maneira eficiente, graças a detecção nas etapas iniciais, pois as reações expansivas geralmente se manifestam depois de certo tempo.

\subsection{Agregado}

A análise química dos agregados constatou a presença de quartzo, feldspato potássico e calcossódico, muscovita e pirrotina, esta última em abundante quantidade. O resultado mais relevante foi a identificação de faixas de sulfetos de poucos milímetros de largura, distantes de maneira mais ou menos regular.

A Fig. 3 [15] apresenta as imagens obtidas através de microscopia óptica e eletrônica de varredura realizadas nos agregados da barragem.
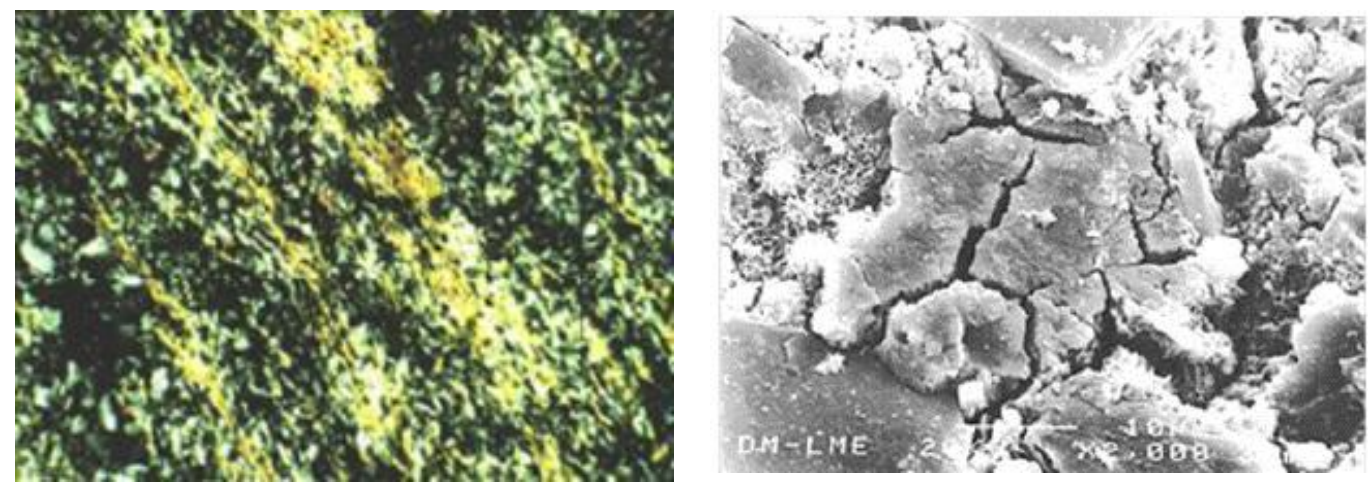

Figura 3: Microscopia óptica e eletrônica de varredura dos agregados da barragem de Graus.

A microscopia óptica mostra faixas de filossilicatos (em amarelo), alternando com massas de quartzo-feldspática (cinza) e minerais opacos (pirrotina). Com a microscopia eletrônica de varredura se observa um detalhe do aspecto dos óxidos de ferro existente na amostra. A morfologia ressalta a existência de uma capa de óxidos de ferro nas amostras dos agregados, o que proporciona um primeiro indício sobre a natureza dos processos de degradação dos materiais.

\section{Problemática}

As principais manifestações patológicas apresentadas na barragem são fissuras, alterações visuais, produtos de reação e movimentos não recuperáveis, localizados no corpo da barragem e nas construções auxiliares, descritos nos itens 2.1.1 e 2.2.2, respectivamente.

\subsection{Fissuração e alterações visuais}

Desde 1986 é possível observar alterações visuais na superfície em tons de ocre juntamente com as fissuras mapeadas, em diferentes regiões e elementos auxiliares da barragem (Fig. 4 [15]). As fissuras mapeadas observadas podem indicar uma primeira manifestação de um processo de reação álcali-agregado e a coloração ocre indica que a principal causa dos danos é a oxidação de um sulfeto de ferro associada a reação sulfática interna. 
Estes sintomas se manifestavam ao longo da crista da barragem e eram mais significativos na região do bloco 5, sendo menos intensos nos blocos das extremidades. Algumas fissuras (horizontais e verticais) localizadas foram observadas nos poços de acesso aos pêndulos e apresentam aberturas superiores a $2 \mathrm{~mm}$, conforme Fig. 5 [15].
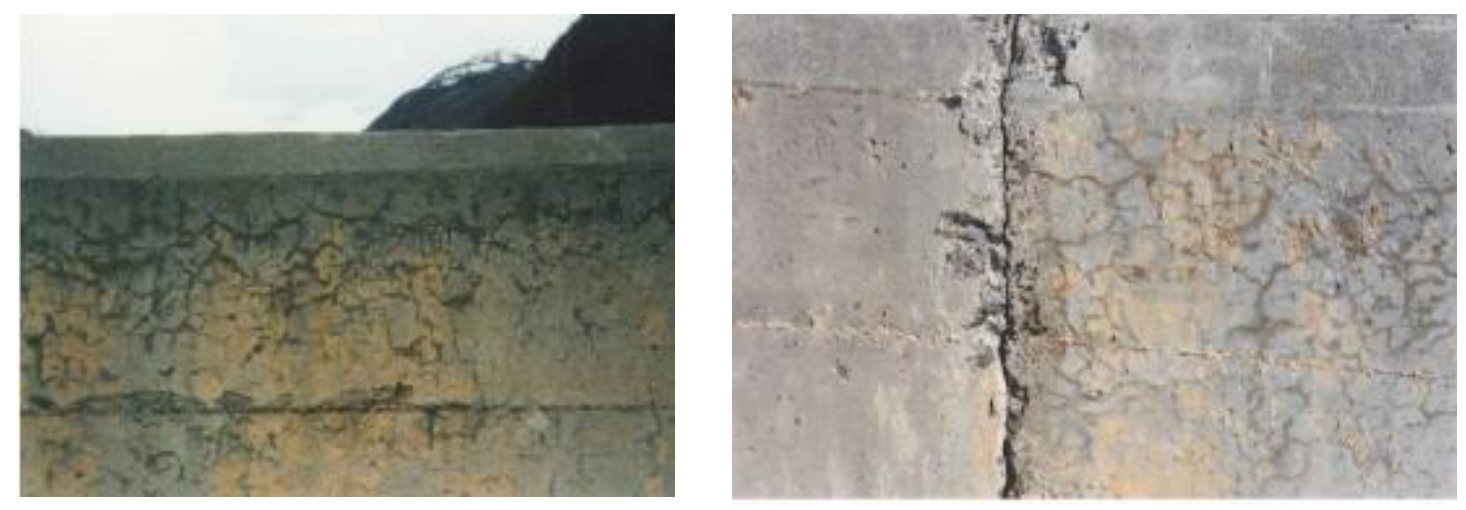

Figura 4: Fissuras e alteração na coloração em 26/04/1988 e em 12/03/1991 na mureta da crista.
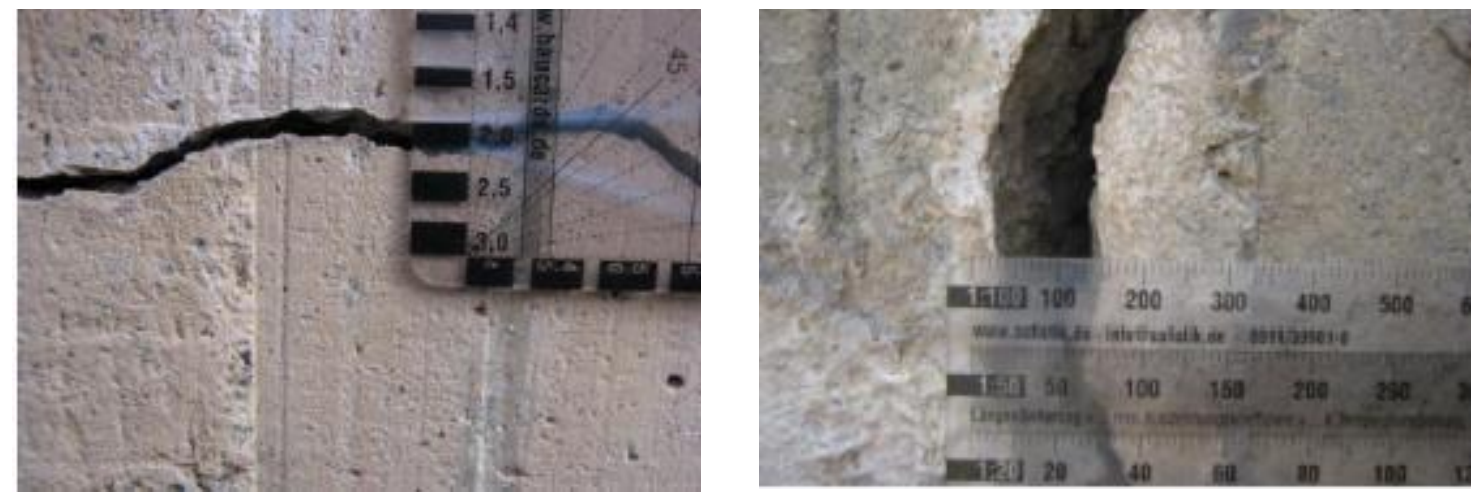

Figura 5: Fissuras com abertura superior a 2mm em 14/07/2009.

Os problemas relacionados à fissuração na barragem de Graus de acordo com [16] são:

- Juntas de dilatação marcadas e sem conhecimento real do estado das juntas no corpo da barragem;

- Juntas frias de concretagem marcadas e com problemas de circulação de água;

- Desplacamento de uma capa superficial de concreto principalmente na região de movimento do nível de água do reservatório, com espessura entre 0,5 e 1 $\mathrm{cm}$, agravado pela circulação excessiva de água e efeito da ação gelo-degelo;

- Microfissuração avançada nos pilares hidráulicos que formam os vertedouros da barragem;

- Fissuração e degradação avançada da crista; 
- Fissuras em pequena quantidade na mureta da crista;

- Fissuração mapeada tanto no corpo da barragem (elementos em massa) como em elementos de concreto armado.

Em setembro de 1999 foram iniciados os trabalhos de intervenção com execução dos reparos, sendo aplicadas resinas epóxi e poliuterano na maior parte dos casos. Os reparos foram realizados tanto em montante como nas juntas frias, nas fissuras mapeadas e nas juntas de dilatação, com a finalidade de evitar a percolação de água. O concreto deteriorado foi restaurado para prevenir falhas localizadas e a degradação progressiva do mesmo.

Os danos causados pelas fissuras são mais significativos nas regiões que possuem carregamentos externos, por exemplo, os pilares hidráulicos. Foi observado que a fissuração mapeada estava mais marcada com o passar do tempo.

\subsection{Deslocamentos}

O modelo cinético proposto por Moura [13] demonstra os movimentos horizontais e verticais na crista da barragem para as expansões causadas pela RSI. Este modelo determina a evolução no tempo da RSI em função da cinética das reações de oxidação dos sulfetos de ferro e do transporte de oxigênio (por difusão) no interior da estrutura. Para os movimentos causados pela RAA, o modelo cinético utilizado foi proposto por Ulm et al. [17]. Este modelo determina a evolução no tempo da RAA em função da temperatura, para isso é necessária uma análise térmica do bloco. Conforme estes modelos apresentados em Aguado et al. [15], a Fig. 6 apresenta um esquema dos deslocamentos horizontais e verticais da RSI e RAA para a crista da barragem.
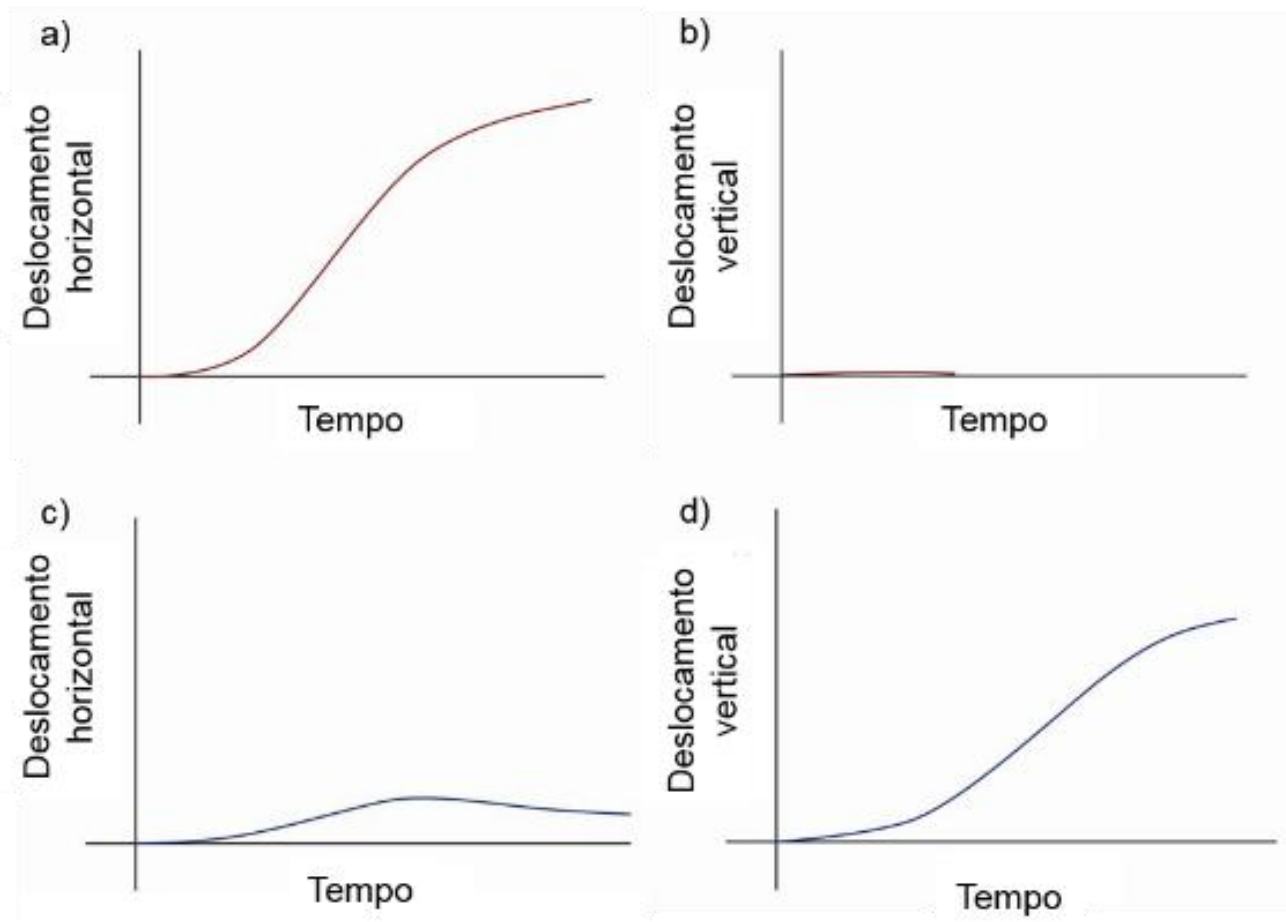

Figura 6: Esquema dos deslocamentos horizontais e verticais na crista da barragem devidos a ação da RSI (a) e (b), RAA (c) e (d). 
Os deslocamentos horizontais e verticais apresentados por ambas as reações possuem evolução e magnitude distintas. Para a RSI, os deslocamentos horizontais se desenvolvem com maior intensidade, enquanto que para a RAA, os maiores valores são observados nos deslocamentos verticais.

A coleta de dados registrados durante o período compreendido entre 1981 e 1986 permitiu detectar a existência de um comportamento anômalo na barragem, refletindo em um movimento horizontal não recuperável da crista. Para encontrar a causa destes deslocamentos foram realizadas diversas atuações, como a verificação das medidas das bases localizadas nas ombreiras e o estudo da fundação.

A Fig. 7 apresenta a evolução dos deslocamentos horizontais e verticais registrados na crista para os 7 blocos que compõem a barragem de Graus.
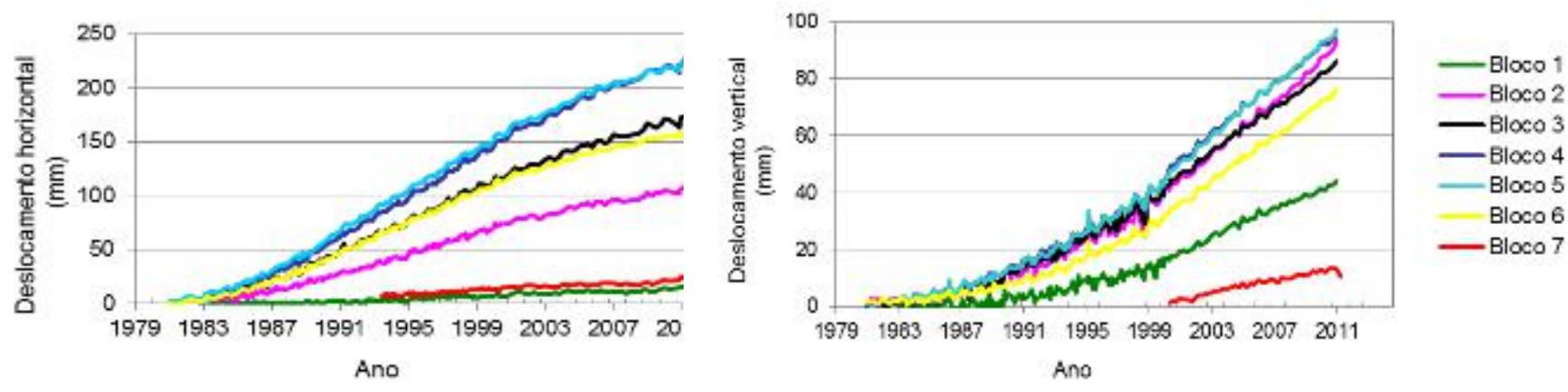

Figura 7: Deslocamentos horizontais e verticais medidos na crista.

$\mathrm{Na}$ Fig. 7 é possível observar valores elevados de deslocamentos horizontais em vários blocos, chegando a $220 \mathrm{~mm}$ a montante nos blocos 4 e 5 (os de maior magnitude). Os deslocamentos verticais consideráveis atingem elevações de $97 \mathrm{~mm}$ (também no bloco 5). Pode-se constatar que a magnitude do deslocamento horizontal no bloco 5 é $126 \%$ superior ao deslocamento vertical deste bloco.

Além disso, se pode verificar a tendência de estabilização dos deslocamentos horizontais em todas as bases aproximadamente no ano de 1999. Essa mesma tendência de estabilização nos deslocamentos verticais não é observada, pois aproximadamente neste mesmo ano, os movimentos se intensificam.

Observando os valores calculados (Fig. 6) da evolução dos deslocamentos verticais causados pela RSI, atuando unicamente, constata-se que eles não correspondem ao comportamento representado pelos valores medidos na barragem (Fig. 7). Este fato é um indício que os deslocamentos verticais encontrados não podem ser atribuídos apenas a esta reação expansiva. Desta forma é possível supor a existência de uma reação secundária, RAA que poderia em algum momento desenvolver-se juntamente com o ataque sulfático, justificando os deslocamentos verticias medidos na barragem.

A Fig. 8 apresenta os deslocamentos horizontais e verticais medidos nas bases da galeria da barragem. 

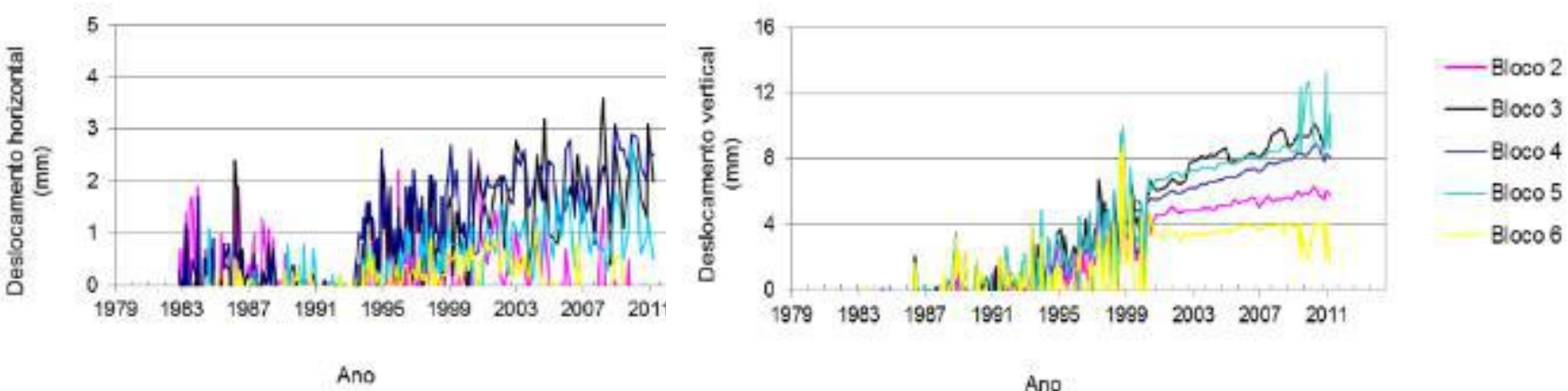

Figura 8: Deslocamentos horizontais e verticais medidos na galeria.

Pode-se observar na Fig. 8 que os deslocamentos horizontais registrados são de baixa magnitude e não apresentam uma clara tendência que indique movimentos não recuperáveis. Os deslocamentos verticias, com elevações máximas compreendidas entre 4 e 12mm, apresentam movimentos não recuperáveis na galeria, percebidos, sobretudo a partir de 1995, atingindo a magnitude de 10 mm no bloco 5 em 2011.

\subsection{Microscopia eletrônica de varredura}

Para comprovar a hipótese de duas reações expansivas na barragem foi realizado o estudo com MEV, o resultado é descrito a seguir:

A Fig. 9 apresenta a microscopia eletrônica de varredura de um testemunho extraído da galeria, a amostra selecionada para a realização do ensaio estava mais próximas a extremidade superficial do testemunho.

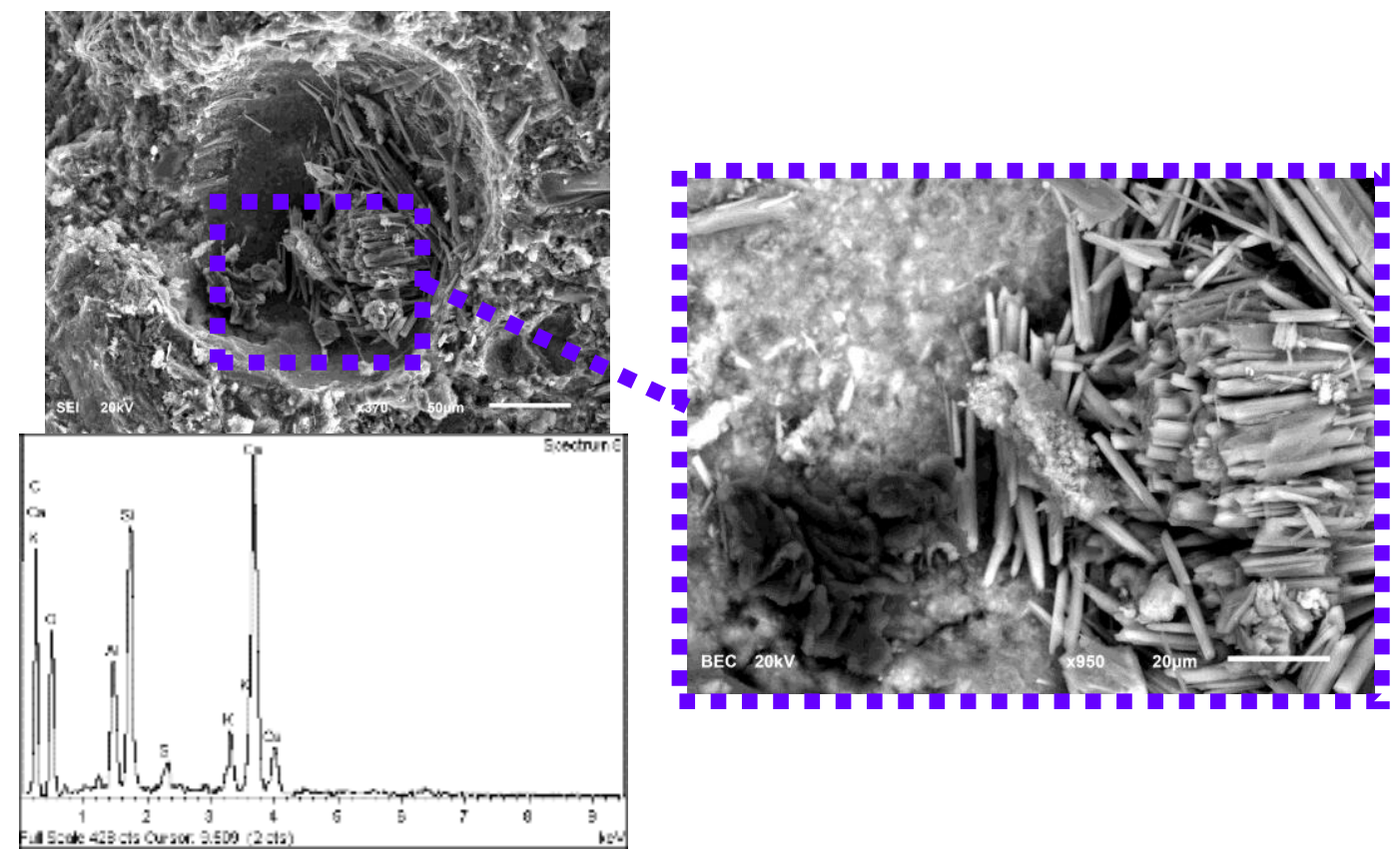

Figura 9: Poro com agulhas de etringita e outros produtps de precipitação.

O poro apresenta formações de agulhas, típicas do crescimento da etringita assim como outros produtos de precipitação. A análise dos mesmos mediantes EDX mostrou uma composição característica do gel da reação alcali-agregado. 
Na Fig. 10 desta amostra se evidencia presença de gel da reação álcali-silica recobrindo a formação das agulhas de etringita (ampliações de x190, x450 e x3000). Esta evidencia embasa a hipótese de que a reação álcali-arido tenha ocorrido após a precipitação da etringita associada a reação sulfática interna.

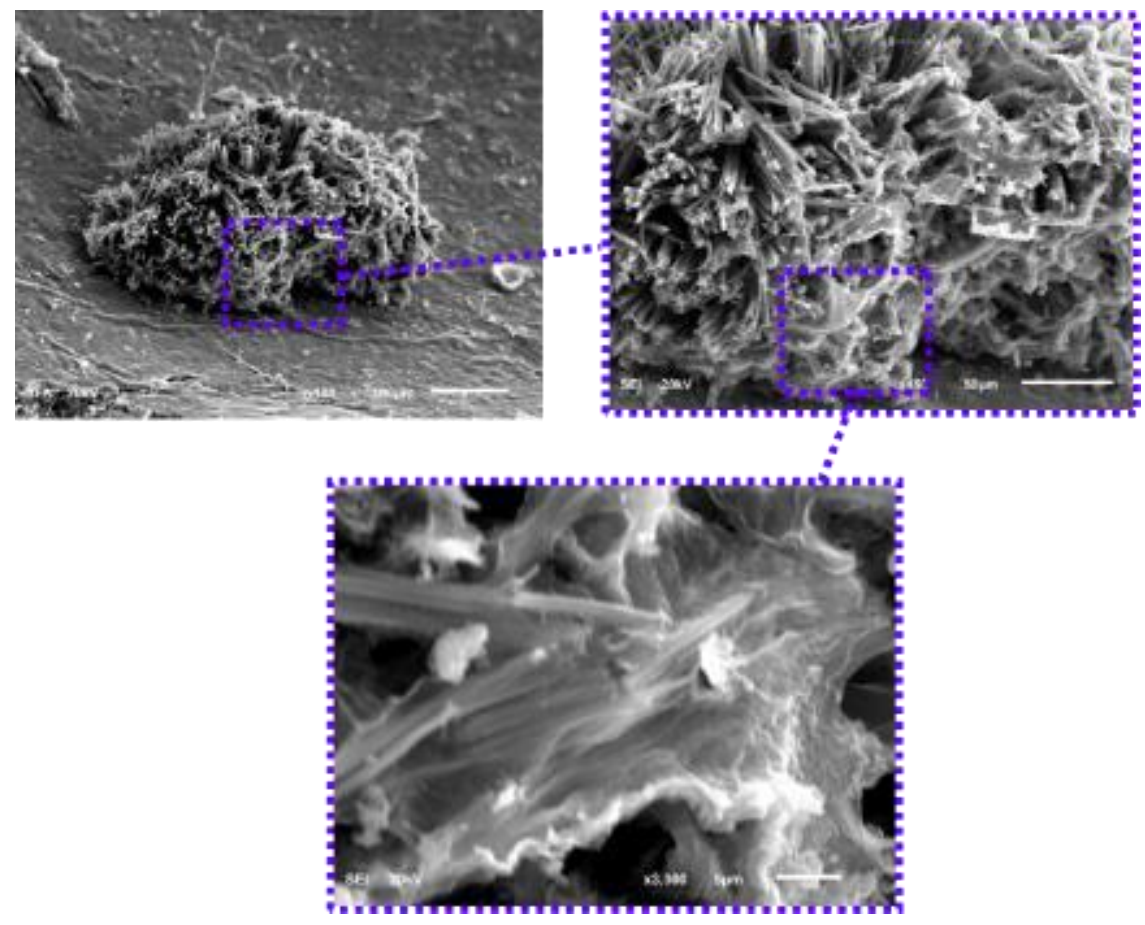

Figura 10: Fossilização da etringira por parte do gel da reação álcali-agregado.

O estudo com microscopia eletrônica de varredura permitiu confirmar a presença de duas reações de degradação no concreto da barragem de Graus, confirmando a hipótese de que primeiro teve lugar ao ataque sulfático interno e posteriormente, teve lugar a uma reação álcali-agregado mais lenta, esta hipótese é reforçada pelas evidências de fossilização da etringita por parte dos produtos da reação álcaliagregado.

\section{Conclusões}

As principais conclusões obtidas a partir do estudo da análise dos deslocamentos e inspeção visual são:

- Se observa um avanço nos sintomas da degradação do concreto (largura e comprimento das fissuras, movimentos visuais de alinhamentos, movimentos entre blocos, etc.). As fissuras observadas podem indicar uma primeira manifestação de um processo de reação álcali-agregado, que se desenvolve com o tempo, cujas características são similares às causadas por uma reação de expansão;

- Os danos se manifestam tanto em zonas de concreto massa como de concreto armado (muretas e estruturas auxiliares), o que mostra uma potencialidade expansiva importante; 
- A coloração ocre indica que a principal causa dos danos é a oxidação de um sulfeto de ferro, sem descartar outras expansões possíveis, não detectável a olho nu, ou porque estão cobertas pelas evidência de reação sulfática interna;

- Os deslocamentos em montante foram detectados em um período de tempo importante (10-15 anos) desde a execução e início das atividades da barragem, o que parece apontar para um processo de expansão com o tempo nos materiais constituintes;

- Os deslocamentos registrados (horizontais e verticais) nos diversos blocos da barragem ao longo dos anos, desde o início da instrumentação em 1981, mostram inequivocadamente os movimentos não recuperáveis. Com deslocamentos horizontais da magnitude de $220 \mathrm{~mm}$ a montante nos blocos 4 e 5 (blocos mais significativos) e deslocamentos verticais de $97 \mathrm{~mm}$ no bloco 5. Sendo descartadas outras causas, os movimentos não recuperáveis parecem corresponder as expansões no concreto;

- A ação do ASI está localizada principalmente em uma zona próxima jusante (região em contato com o ar), tendendo a gerar deslocamentos horizontais de magnitude muito superior aos deslocamentos verticais;

- O estudo com microscopia eletrônica de varredura confirma a presença de duas reações de degradação no concreto da barragem de Graus, apresentando a fossilização da etringita por parte dos produtos da reação álcali-agregado;

- Existem mecanismos de expansão com cinéticas distintas atuando na barragem, uma mais rápida (ASI, responsável principalmente pelos deslocamentos horizontais) e outra mais lenta (RAA, responsável pelos deslocamentos verticais).

\section{Agradecimentos}

O primeiro autor gostaria de agradecer ao CNPq - Conselho Nacional de Desenvolvimento Científico e Tecnológico - pela bolsa concedida (processo 205215/2014-9).

\section{Bibliografia}

[1] ICOLD-CIGB (1997) Concrete Dams - Control and Treatment of Cracks Bulletin 107 of the International Commission on Large Dams. Paris. Acessado em:maio/2015.

http://www.icold-cigb.org/GB/World register/general synthesis.asp?IDA=206

[2] DIAMOND, S. (1975) A review of alkali-silica reaction and expansion mechanisms - 1: alkalis in cements and in concrete pore solutions. Cement and Concrete Research, 5: 329-345. 
[3] PAULON, V. A.(1981) Reação Álcali-Agregado em Concreto. Dissertação (mestrado), Escola politécnica da Universidade de São Paulo, São Paulo, Brasil.

[4] SAOUMA, V.; MARTIN, R. A.; HARIRI-ARDEBILI, M. A.; KATAYAMA, T. (2015) A mathematical model for the kinetics of the alkali-silica chemical reaction. Cement and Concrete Research, 68: 184-195.

[5] CASANOVA, I.; AGUADO, A.; AGULLÓ, L. (1997) Aggregate expansivity due to sulfide oxidation - II. Physico-chemical modeling of sulfate attack. Cement and Concrete Research, 27, ํ․ 11, 1627-1632.

[6] OLIVEIRA, I. (2011) Reacción sulfática interna en presas de hormigón cinética del comportamiento. Tesis doctoral, Universitat Politècnica de Catalunya, Barcelona, Espanha.

[7] SEGARRA FORADADA, J. (2005) Envejecimiento de presas por reacciones expansivas. Minor thesis, Universitat Politècnica de Catalunya, Barcelona, Espanha.

[8] ANDRIOLLO, R. (2007) Expansion effects of pyrite in the rock matriz of the Rio Descoberto Dam. Granada, Espanha. Acessado em: junho/2015. http://www.andriolo-eng.com/images/publicacoes/P143.pdf

[9] GOMIDES, M. de J.; HASPARYK, N. P.; ANDRADE, M. A. S. de; BITTENCOURT, R. M. (2005) Investigação de agregados contendo sulfetos para utilização em estruturas de concreto. XXVI Seminário nacional de grandes barragens. Comitê brasileiro de barragens. Goiás, Brasil.

[10] OLIVEIRA, I.; CAVALARO, S. H. P.; AGUADO, A. (2013) New Unreacted-Core Model to Predict Pyrrhotite Oxidation in Concrete Dams. Journal of Materials in Civil Engineering, 25, Issue 3, 372-381.

[11] OLIVEIRA, I.; CAVALARO, S. H. P.; AGUADO, A. (2014) Evolution of pyrrhotite oxidation in aggregates for concrete. Materiales de Construcción, 64, Issue 316.

[12] CAMPOS, A.; LOPEZ, C.; AGUADO, A. (2010) Análisis meso-mecánico del hormigón bajo la acción de procesos expansivos internos. XXVII Encuentro del Grupo Español de Fractura/12 ${ }^{a}$ Jornadas de Fractura de SPM. Porto, Portugal, 283-288.

[13] MOURA, A. C. de. (2012) Análisis numérico de presas de hormigón bajo acciones expansivas. Barcelona: Tesis doctoral, Universitat Politècnica de Catalunya, Barcelona, Espanha.

[14] SPANCOLD - Base de dados de barragem de concreto com expansões: Graus. Acessado em: abril/2015 http://spancold.es/Paginas/inventario presas.asp

[15] AGUAdO, A.; CAMPOS, A.; CAVAlARO, S. H. P.; CHICHÓN-PAYÁ, S.; LÓPEZ, C. M., SEGURA, I. (2014) Estudio del comportamiento de la presa de Graus. Convenio CTT-8400. Barcelona, Espanha.

[16] CAÑABATE, M. (2003) Reparación de los paramentos de aguas arriba de las presas de Graus-Torán y Tavescán. Revista Cimbra, 353, Julio - Agosto. 
GOBBI, A; CAVALARO, S.H.P; MEDEIROS, M.H.F, ESTUDO DO COMPORTAMENTO DA BARRAGEM DE GRAUS. $2^{\circ}$ Simpósio Paranaense de Patologia das Construções (20 SPPC), artigo 2SPPC1025, pp. 303-314, 2017. DOI: 10.4322/2SPPC.2017.025

[17] ULM, F.J.; COUSSY, O.; KEFEI, L.; LARIVE, C. (2000) Thermo-ChemoMechanics of ASR Expansion in Concrete Structures. ASCE Journal of Engineering Mechanics, 126, n. 3, 233-242. 